\title{
MECANISMOS DE REGULACIÓN DEL REAL SITUADO: UNA APROXIMACIÓN A LA EFICIENCIA DE LOS RECURSOS FISCALES DESTINADOS AL EJÉRCITO DE CHILE EN EL SIGLO XVII $^{1}$
}

\author{
Antonio Luis Rodríguez Ridao ${ }^{2}$ \\ Universidad Autónoma de Chile \\ Universidad Complutense de Madrid \\ Luisa Consuelo Soler Lizarazo ${ }^{3}$ \\ Universidad Autónoma de Chile \\ DOI: 10.17533/udea.tempus.n6a02
}

\section{Resumen}

El artículo analiza la eficiencia de los recursos fiscales remitidos desde el virreinato peruano para el satisfactorio sostenimiento de la defensa de la Frontera chilena. Así, se deduce que a pesar de remitirse el real situado de forma íntegra, a menudo resultó insuficiente para cubrir los salarios de los soldados chilenos. Ello debido, principalmente, a los propios mecanismos instaurados para la regulación del caudal por parte de los responsables financieros en su gestión, tanto en Lima como en Concepción, y a la imposición de un mecanismo de dominación de los capitales privados sobre la Real Hacienda. En efecto, siguiendo la hipótesis trazada por Alejandra Irigoin y Regina Grafe, se puede concluir que el situado chileno estuvo supeditado a la financiación privada y que, en consecuencia, grupos de mercaderes pudieron obtener beneficios sustanciosos a partir del manejo de este subsidio en perjuicio de los propios soldados.

Palabras clave: Real Situado, Ejército, Real Hacienda, mapa del pagamento, creces, crédito, capital privado, mercaderes.

\footnotetext{
Abstract

${ }^{1}$ Este artículo forma parte del Proyecto Fondecyt Iniciación Chile No. 11130190.

${ }^{2}$ Licenciado en Historia y Máster Oficial en Estudios Americanos por la Universidad de Sevilla. Doctorando en Historia por la Universidad Autónoma de Chile. antoniorodriguez@uautonoma.cl

${ }^{3}$ Profesora Titular del Programa Doctorado en Historia, Universidad Autónoma de Chile. Doctora en Historia por la Universidad Iberoamericana de México. lsolerl@uautonoma.cl
} 
This research article analyzes the effectiveness of fiscal resources sent from the Peruvian Viceroyalty for the successful maintenance of the defense in the Chilean Border. In this way is deducted that the Real Situado was insufficient to cover the salaries of Chilean soldiers despite being sent in full. This was due to the mechanisms in place to regulate the Real Situado by the financial agents in charge of managing it both in Lima and in Concepción. It was also due to the imposition of a mechanism of domination of private equity over the Royal Treasury. Indeed following the hipothesys of Alejandra Irigoin and Regina Grafe we conclude that the Chilean situado was subordinated to private financing. And consequently groups of traders might have accrued great profits from the management of this subsidy to the detriment of the soldiers.

Keywords: Real Situado, Chilean Army, Royal Treasury, “mapa del pagamento”, “creces”, credit, private equity, traders.

\section{Introducción.}

Durante época colonial, el reino de Chile fue considerado por la burocracia administrativa de España e Indias como un área estratégica cuya preservación de los enemigos de Europa se estimaba inapelable. No obstante, fue el llamado "enemigo doméstico" el que supeditó la realidad y el desarrollo de la colonia; en efecto, desde el mismo momento de iniciarse la ocupación chilena, los conquistadores españoles hubieron de enfrentar la resistencia brindada por los pueblos nativos localizados al sur del río Bío-Bío. Al respecto, tras varias décadas de conflicto, la insubordinación iniciada por el elemento indígena en Curalaba en 1598 terminó por convertirse en el componente último que instigó a las autoridades peninsulares a la comprensión de que sin un ejército profesional y con el sostén financiero de la guerra supeditado a las reservas económicas de los habitantes de aquel reino, el desenlace de ésta implicaría la renuncia definitiva al establecimiento de asentamientos españoles en aquel territorio. Estas circunstancias, en definitiva, forzaron a la Corona a ejecutar una transformación del régimen militarista chileno, creándose para ello un ejército profesional con el quehacer de contener el avance indígena en la línea de frontera que se estableció al sur del río Bío-Bío.

Junto a la creación del ejército profesional, la Corona activó el mecanismo fiscal para satisfacer el pago de la tropa y las necesidades que aquel conflicto demandaba, instaurando 
un situado que debió suministrarse anualmente desde la tesorería real de Lima a partir de los excedentes generados por los aranceles que gravaban la producción de las minas argentíferas de Potosí ${ }^{4}$. Su cuantía quedó fijada en 212.000 ducados -o 292.279 pesos de a ocho reales-, una transferencia monetaria a la que se dotó de carácter anual y que permaneció inmutable durante todo el siglo XVII ${ }^{5}$. De acuerdo a la tesis de Marcello Carmagnani, el situado se constituyó en la más significativa fuente de ingresos de la región receptora durante el siglo $\mathrm{XVII}^{6}$ y generador, en consecuencia, de un aumento de la liquidez en el mercado local, resguardada y fluctuante, no obstante, por la tributación de la hacienda peruana. A pesar de ello, son numerosos los testimonios aparecidos en misivas de gobernadores y otros informantes, principalmente en la segunda mitad del siglo XVII, que advirtieron a las autoridades metropolitanas del ruinoso estado del ejército y de la extenuación y falta de obediencia de los soldados chilenos. $\mathrm{O}$, lo que es lo mismo, testimonios que cuestionaron la eficiencia de la referida ayuda para cumplir con su ineludible y primordial cometido: el sostenimiento y abastecimiento de las guarniciones militares valedoras de la defensa chilena.

Al respecto, en el presente artículo se pretende desvelar la razón principal por la cual los excedentes fiscales remitidos desde las cajas peruanas resultaron a menudo insuficientes, aun llegando íntegros de Lima, para cubrir las necesidades fundamentales de los soldados chilenos. Para responder la incógnita creemos necesario describir y examinar la manera en que los responsables financieros en la gestión del situado regularon el flujo de caudales que integraba la ayuda, tanto en Lima como en Concepción - esta última, ciudad capital de aquel territorio fronterizo chileno y una de las circunscripciones fiscales de la administración imperial-, y la forma en que liquidaban las cargas y obligaciones inherentes a la misma. De

\footnotetext{
${ }^{4}$ Álvaro Jara, El Imperio español en América (1700-1820). Una historia económica (Santiago de Chile: Editorial Sudamericana, 2011), 204-205.

${ }^{5}$ En realidad, en el momento de instaurarse el situado chileno en el año 1600, Felipe III fijó su cuantía en 60.000 ducados de plata (real cédula de 21 de marzo de 1600) que, no obstante, incrementó dos años después a 120.000 (real cédula de 24 de septiembre de 1602) y, en 1604, a 140.000 (real cédula de 4 de septiembre de 1604). Más tarde, las urgencias por liquidar la guerra de Arauco, junto a las persistentes peticiones de socorro consignadas por las autoridades chilenas, instigaron a la Corona, finalmente, a gravar su cuantía en 212.000 ducados, tal y como se ha referido (real cédula de 5 de diciembre de 1606). A comienzos del siglo XVIII, no obstante, en un momento en que paradójicamente los costos de defensa en América aumentaron extraordinariamente en función de los envíos en metálico a la metrópoli, la realidad refleja como este gasto situado a Chile desde el virreinato peruano fue rebajado a 100.000 pesos.

${ }^{6}$ Marcello Carmagnani, Los mecanismos de la vida económica de una sociedad colonial: Chile (1680-1830) (Santiago de Chile: DIBAM, 2001), 126-127.
} 
igual modo, precisamos aproximarnos al estudio de los mecanismos y las relaciones de dependencia entre el real situado -o las haciendas de Lima y Concepción- y los capitales privados, y descubrir, en última instancia, quiénes fueron en la práctica los colectivos beneficiarios de la subvención en perjuicio de los soldados.

Han sido varios los autores que se han aproximado al estudio de la maquinaria militar en Chile durante el periodo colonial y, en particular, al examen del situado. Roberto Oñat fue el pionero en el establecimiento de una síntesis evolutiva del régimen legal del ejército chileno, exponiendo buena parte de la documentación relativa a la estructura militar, los sueldos y al proceso administrativo de la entrega del situado ${ }^{7}$. Álvaro Jara, por otra parte, reveló la coyuntura que propició el origen del gasto situado a Chile desde las cajas peruanas y la creación de un ejército estatal en la frontera chilena ${ }^{8}$; décadas después, en un trabajo inconcluso y de publicación póstuma, Jara analizó también el costo defensivo y militar chileno a escala imperial durante el siglo XVIII. Por su parte, José Manuel Díaz Blanco contextualizó la proposición del Consejo de Indias al monarca para la creación de un ejército profesional en Chile -el primero en el continente americano sufragado en su parte principal por la Corona a través de un situado- en el peligro que podría suponer una potencial alianza, inmediata o a futuro, entre los "indígenas rebeldes" y los "enemigos de Europa", para la preservación de un territorio estimado como puerta de entrada al rico virreinato peruano 9 .

De igual forma, Fernando Silva Vargas, en certeros trabajos, estableció los vínculos administrativos y fiscales entre Chile y Perú ${ }^{10}$. No obstante, fueron las publicaciones de Juan Eduardo Vargas Cariola las que con más rigor indagaron sobre el ejército chileno, aproximándose, en este sentido, al estudio de su financiación durante el siglo XVII. Al respecto, sus aportes insertaron, entre otras materias de sumo interés, un acercamiento al

\footnotetext{
${ }^{7}$ Roberto Oñat, Régimen legal del ejército en el Reino de Chile: notas para su estudio (Santiago de Chile: Ed. Del Pacífico, 1953).

${ }^{8}$ Álvaro Jara, Guerra y sociedad en Chile: la transformación de la Guerra de Arauco y la esclavitud de los indios (Santiago de Chile: Editorial Universitaria, 1971).

9 José Manuel Díaz Blanco, Razón de Estado y buen gobierno. La Guerra Defensiva y el imperialismo español en tiempos de Felipe III (Sevilla: Universidad de Sevilla - Secretariado de Publicaciones de la Universidad de Sevilla, 2010), 79-93.

${ }^{10}$ Fernando Silva Vargas, "Esquema de la Hacienda Real en Chile indiano (siglos XVI y XVII)", Revista Chilena de la Historia del Derecho no. 4 (1965): 208-250; "Perú y Chile. Notas sobre sus vinculaciones administrativas y fiscales (1785-1800)", Historia no. 7 (1968): 147-203; Poder y redes: el gobernador de Chile don Francisco Ibáñez de Peralta (1700 - 1709) (Santiago de Chile: Academia Chilena de la Historia, 2013).
} 
análisis de las entradas y los gastos del ejército, y al estudio de los "descuentos" aplicados por las autoridades peruanas al situado. Su obra, como se observará, constituye el punto de partida imperativo de este trabajo ${ }^{11}$. Por su parte, Patricia Cerda-Hegerl examinó la sociedad militar en la frontera de Chile durante los siglos coloniales e insistió, entre otros asuntos, en la dependencia que se produjo entre los hacendados de la región con el situado, aspecto que se verá reflejado en nuestras conclusiones ${ }^{12}$. Como ya se ha adelantado, Marcello Carmagnani señaló el papel revitalizador de esta transferencia de excedentes fiscales desde el virreinato del Perú para la economía de Concepción, al igual que Armando de Ramón y José Manuel Larraín, quienes vincularon el situado con el mercado exterior regional ${ }^{13}$. Por último, más recientemente, Margarita Gascón ha estudiado la articulación de Mendoza, Córdoba y Buenos Aires en el circuito de la ganadería comercial a Chile para el abastecimiento del ejército de Arauco, atisbando aquel conflicto fronterizo como dinamizador de la producción y mercantilización de recursos en toda la banda sur del virreinato peruano $\mathrm{y}$, en consecuencia, descubriendo las posibilidades de lucro de determinados grupos de mercaderes en torno a un situado que las propiciaba ${ }^{14}$.

En cuanto al resto de demarcaciones coloniales americanas, son numerosos los autores que han centrado sus estudios en la faceta del gasto militar y en el sistema de situados, si bien, la mayoría de éstos han sido circunscritos geográficamente al ámbito circuncaribeño ${ }^{15}$

\footnotetext{
${ }^{11}$ Juan Eduardo Vargas Cariola, "Los Austrias y el ejército de Chile", Revista Chilena de Historia del Derecho no. 9 (1983): 355-370; "Financiamiento del ejército de Chile en el siglo XVII", Historia no. 19 (1984): 159202; "Antecedentes sobre levas en Indias para el ejército de Chile en el siglo XVII (1541-1662)", Historia no. 22 (1987): 335-356; "Notas sobre el gobierno militar en Indias: el caso del ejército de Chile en el siglo XVII", Revista Chilena de Historia del Derecho no. 15 (1991): 219-234; "Estilo de vida en el Ejército de Chile durante el siglo XVII", Revista de Indias no. 53 (1992): 425-458.

${ }^{12}$ Patricia Cerda-Hegerl, Fronteras del Sur. La región del Bio Bio y la Araucanía chilena, 1604-1883 (Temuco: Universidad de la Frontera, 1996).

${ }^{13}$ Armando de Ramón, Historia urbana. Una metodología aplicada (Buenos Aires: Clacso - Ediciones Siap, 1978); Armando de Ramón y José Manuel Larraín, Orígenes de la vida económica chilena: 1659-1808 (Santiago de Chile: Centro de Estudios Públicos, 1982).

${ }^{14}$ Margarita Gascón, "La articulación de Buenos Aires a la Frontera Sur del Imperio español, 1640-1740", Anuario IEHS no.13 (1998): 193-213; "Comerciantes y redes mercantiles del siglo XVII en la frontera sur del Virreinato del Perú", Anuario de Estudios Americanos 57, no. 2 (2000): 413-448; "La defensa del sur del virreinato del Perú en el siglo XVII: la estrategia imperial y la agencia de la naturaleza", Revista TEFROS 6, no. 1 (2008): 1-20.

${ }^{15}$ John Jay TePaske, La Real Hacienda de Nueva España, la Real Caja de México: 1576-1816 (México, D.F.: Instituto Nacional de Antropología e Historia, 1976); John Jay TePaske y Herbert S. Klein, The Royal Treasuries of the Spanish Empire in America (Durham, N.C.: Duke University Press, 1982); Allan J. Kuethe, "Guns, Subsidies and Commercial Privilege: Some Historical Factors in the Emergence of the Cuban National Character, 1763-1815”, Cuban Studies no. 16 (1986): 123-138; Braulio L Flores Morón, "Los situados del Río
} 
-es decir, a las regiones coincidentes con los grandes centros mercantiles y de canalización de recursos-, y para un marco cronológico bien concreto, el siglo XVIII, en el que el volumen total de caudales que integraron los situados se incrementó de forma notable ${ }^{16}$. Obviando, por ahora, el debate existente en torno a si estos excedentes fiscales situados llegaron a constituirse en el motor de las economías locales para cada una de las regiones receptoras ${ }^{17}$,

de la Plata en el siglo XVIII", Temas de Historia Militar no. 2 (1988): 207-220; John Jay TePaske y Herbert S. Klein, Ingresos y egresos de la Real Hacienda de Nueva España (Culhuacán: Instituto Nacional de Antropología e Historia, 1988); Carlos Marichal y Matilde Souto, "Silver and Situados: New Spain and the Financing of the Spanish in the Caribbean in the XVIII century", The Hispanic American Historical Review 74, no.4 (1994): 587-613; Johanna von Grafenstein, "El papel de la Nueva España como fuente de recursos para las posesiones españolas del Gran Caribe (1779-1784)", Homines. Revista de Ciencias Sociales 20, no.2 (2000): 338-355; José Manuel Serrano, "El situado en la administración militar indiana: los casos de Santa Fe y Quito, 1700-1788", Revista de Historia Militar no. 92 (2002): 147-184; José Manuel Serrano, "El gasto naval en España e Indias (1715-1759): el caso de Tierra Firme", Revista de historia naval 20, no. 77 (2002): 25-34; José Manuel Serrano, "El factor humano en la defensa de Tierra Firme: sueldos en Cartagena de Indias, 1700-1788", Temas Americanistas no. 16 (2003): 64-80; José Manuel Serrano, Fortificaciones y tropas: el gasto militar en Tierra Firme, 1700-1788 (Sevilla: Universidad de Sevilla-CSIC-Diputación de Sevilla, 2004); Allan J. Kuethe, "El situado mexicano, los azucareros y la fidelidad cubana: comparaciones con Puerto Rico y Nueva Granada", en Las Antillas en la era de las luces y la revolución, Coord José Antonio Piqueras Arenas (Castillón de la Plana: Siglo XXI, 2005): 301-318; Argelia Pacheco, Una estrategia imperial. El situado de España a Puerto Rico, 1765-1821 (San Juan de Puerto Rico: Instituto Mora, 2005); José Manuel Serrano, "Situados y administración militar en Texas a mediados del siglo XVIII", Temas Americanistas no. 18 (2005): 40-55; María L. Laviana Cuetos, "Excedente fiscal y defensa del Imperio: el situado de Guayaquil a Cartagena en el siglo XVIII", Revista del CESLA no. 11 (2008): 93-104; Johanna von Grafenstein, "Situado y gasto fiscal: la real caja de México y las remesas para gastos militares en el Caribe, 1756-1787", en Guerra y Fiscalidad en la América colonial, siglos XVI-XIX, Coord. Ángelo Alves Carrara y Ernest Sánchez Santiró (México: Instituto Mora, Universidad Federal Juiz de Fora, 2012), 115-142; Adolfo Meisel, "El situado de Cartagena de Indias a fines del Siglo de las Luces", en El secreto del Imperio español: los situados coloniales en el siglo XVIII, Coord. Carlos Marichal y Johanna von Grafenstein (México, D.F.: El Colegio de México, Centro de Estudios Históricos: Instituto Mora, 2012), 193-212: Carlos Marichal y Matilde Souto, "La Nueva España y el financiamiento del imperio español en América: los situados para el Caribe en el siglo XVIII", en El secreto del Imperio español..., 61-94; Johanna von Grafenstein, "El situado novohispano al Circuncaribe, un análisis de su composición, distribución y modalidades de envío, 1791-1808", en El secreto del Imperio español..., 143170; José Manuel Serrano y Allan J. Kuethe, "El situado mexicano y la Cuba borbónica", en El secreto del Imperio español..., 95-114; José Manuel Serrano, "Dominio, presencia militar y situados en Texas a mediados del siglo XVIII", en El secreto del Imperio español..., 237-250; Laura Náter, "Dimensiones y funciones de los situados de tabaco en La Habana del siglo XVIII", en El secreto del imperio español..., 171-192; Yovana Celaya Nández, "El costo fiscal en la defensa del Caribe: la Armada de Barlovento, 1702-1748", en El secreto del Imperio español..., 213-236.

${ }^{16}$ En cuanto a los estudios que han trabajado la financiación y gasto militar en América durante la centuria decimoséptima, ver: José Manuel Serrano Álvarez, Ejército y fiscalidad en Cartagena de Indias: auge y declive en la segunda mitad del siglo XVII (Bogotá: El Áncora, 2006); Rafael Reichert, "El situado novohispano para la manutención de los presidios españoles en la región del Golfo de México y el Caribe durante el siglo XVII", Estudios de historia novohispana no. 46 (2012): 47-81; Luis Alonso Álvarez, "La ayuda mexicana en el Pacífico: socorros y situados en Filipinas, 1565-1816”, en El secreto del Imperio español..., 251-294; Argelia Pacheco Díaz, "Las transferencias fiscales novohispanas a Puerto Rico: siglos XVI - XIX", en El secreto del Imperio español..., 115-142; Yovana Celaya Nández, Alcabalas y situados: Puebla en el sistema fiscal imperial, 1638-1742 (México, D.F.: El Colegio de México Fideicomiso Historia de las Américas, 2010).

${ }^{17}$ Con respecto al papel de los situados en las economías receptoras, la tendencia más generalizada en la historiografía ha sido la de atribuirles una relevancia determinante como mantenedores de los circuitos económicos y comerciales en las respectivas demarcaciones beneficiadas. Juan Marchena sugirió que la 
nos interesa destacar aquellos trabajos que han señalado el papel de las corporaciones de mercaderes y élites locales en la financiación de la defensa del imperio y, más particularmente, en el sistema de situados. Al respecto, Juan Marchena, uno de los pioneros en los estudios históricos concernientes al financiamiento militar en América, hizo hincapié en la idea de que los situados se convirtieron en "un formidable instrumento de presión de los capitales privados sobre la Corona en salvaguarda de sus intereses particulares"18; y, en la misma línea, Alejandra Irigoin y Regina Grafe han sostenido más recientemente cómo el sistema fiscal colonial, y en particular el orientado a la defensa del Imperio, fue dependiente de la financiación privada efectuada por unas élites locales que acabaron beneficiándose del sistema ${ }^{19}$. Así:

En las colonias eran los propios situados los que servían para enriquecer y dar sustento de poder a las élites locales. Ellos funcionaban como lubricante al crear o mantener la demanda de bienes y servicios en las economías locales y los mercados regionales, beneficiándose así estas élites de manera muy significativa $^{20}$.

En efecto, Irigoin y Grafe han centrado su análisis en los mecanismos de "negociación" entre la Corona y las mencionadas élites, principalmente los gremios mercantiles, para la

economía de Cartagena de Indias durante el siglo XVIII estuvo supeditada a la llegada del situado y, apoyado en esta idea, el economista Adolfo Meisel expuso que la economía cartagenera fue dependiente del flujo de caudales procedentes de este socorro. El debate surgió con la respuesta a Meisel de José Manuel Serrano, quien a partir de un exhaustivo análisis del sistema hacendístico de Cartagena de Indias a través de las rentas en ella generadas, sostiene, sin embargo, que los excedentes fiscales remitidos a aquel presidio, si bien actuaron como estimuladores del entramado económico de la ciudad, no llegaron a constituir el componente primario de los ingresos. Ver, respectivamente, Juan Marchena Fernández, La institución militar en Cartagena de Indias en el siglo XVIII (Sevilla: Escuela de Estudios Hispano-Americanos, 1982); Adolfo Meisel Roca, "Crecimiento a través de los subsidios: Cartagena de Indias y el situado, 1751-1810", Cuadernos de Historia económica y empresarial no. 9 (2002): 1-26; “¿Situado o contrabando? La base económica de Cartagena de Indias a finales del siglo de las Luces", en Cartagena de Indias en el siglo XVIII, Coord Haroldo Calvo Stevenson y Adolfo Meisel Roca (Cartagena de Indias: Banco de la República, 2005); José Manuel Serrano Álvarez, "Situados y rentas en Cartagena de Indias durante el siglo XVIII", Temas Americanistas no. 17 (2004): 58-78.

${ }^{18}$ Juan Marchena Fernández, Ejército y milicias en el mundo colonial americano (Madrid: Mapfre, 1992), 152. Ver también: "La financiación militar en Indias: introducción a su estudio", Anuario de Estudios Americanos no. 36 (1979): 81-110; "Financiación militar y situados", Temas de historia militar: $2^{\circ}$ Congreso de Historia Militar no.1 (1988): 261-310; "Capital, créditos e intereses comerciales a fines del periodo colonial: los costos del sistema defensivo americano. Cartagena de Indias y el sur del Caribe", Tiempos de América: Revista de historia, cultura y territorio no. 9 (2002): 3-38.

${ }^{19}$ Alejandra Irigoin y Regina Grafe, "Bargaining for Absolutism. A Spanish Path to Nation-State and Empire Building”, The Hispanic American Historical Review 88, no. 2 (2008): 235-245. Para la realización de este artículo nos hemos basado en la versión traducida: "Absolutismo negociado: la trayectoria hispana en la formación del Estado y el Imperio", en El secreto del Imperio español..., 295-340.

${ }^{20}$ Alejandra Irigoin y Regina Grafe, "Absolutismo negociado...,", 316. 
financiación, entre otras materias, de la defensa imperial. Y, en consecuencia, la consecución de réditos particulares por parte de estos sectores sociales privilegiados a partir de su ineludible participación en el manejo de los caudales procedentes de los situados, ya sea con la venta de alimentos, vestuario y armamento a los diferentes presidios; con el transporte de estas mercancías y capitales; o con el complejo sistema de préstamos a las diferentes reales haciendas, entre otras formas de acumulación de capital. Al respecto, Margarita Suárez ya estudió el destacado papel de los mercaderes peruanos del siglo XVII en las finanzas del virreinato, concediendo especial atención a la cuestión de los préstamos ${ }^{21}$, aspecto trabajado para el ámbito específicamente militar por el profesor José Manuel Serrano ${ }^{22}$. Y si otros trabajos, como los de Allan J. Kuethe, Johanna von Grafenstein o Margarita Gascón, han mostrado cómo las provisiones para las guarniciones militares eran administradas por redes de mercaderes, a nivel local o regional, otros estudios han revelado también cómo la propia conducción del situado ${ }^{23}$ o el reclutamiento privado de soldados por asientos ${ }^{24}$ ofrendaron a particulares la posibilidad de estimar los ejércitos y los situados como objetos de explotación lucrativa. Por último, y en la misma línea, Martin L. E. Wasserman ha dado cuenta también de cómo el real situado remesado al presidio de Buenos Aires brindó a particulares y corporaciones la posibilidad de emplear caudales de la hacienda real en función de sus intereses mercantiles ${ }^{25}$.

Considerando todo este ingente esfuerzo de investigación, en definitiva, el presente artículo constituye un esfuerzo más que apunta en la dirección de los trabajos de Irigoin y Grafe, descubriéndose no sólo como una aproximación a la problemática preludiada acerca de la eficiencia de los recursos fiscales destinados al sostenimiento financiero de la defensa

\footnotetext{
${ }^{21}$ Margarita Suárez, Desafíos trasatlánticos: mercaderes, banqueros y el estado en el Perú virreinal, 16601700 (Lima: Pontificia Universidad Católica del Perú. Instituto Riva-Agüero, 2001). Ver también, de la misma autora, Comercio y fraude en el Perú colonial: las estrategias mercantiles de un banquero (Lima: Instituto de Estudios Peruanos, 1995).

${ }^{22}$ José Manuel Serrano, Fortificaciones y tropas...

${ }^{23}$ Eduardo R. Saguier, "La conducción de los caudales de oro y plata como mecanismo de corrupción. El caso del situado asignado a Buenos Aires por las cajas reales de Potosí en el siglo XVIII", Historia no. 24 (1989): 287-317.

${ }^{24}$ Francisco Andújar Castillo, "La privatización del reclutamiento en el siglo XVIII: el sistema de asientos", Studia histórica. Historia Moderna no. 28 (2003): 123-147; "Guerra, venalidad y asientos de soldados en el siglo XVIII”, Studia histórica. Historia Moderna no. 35 (2013): 235-268.

${ }^{25}$ Martin L. E. Wasserman, "Real Situado y gestión patrimonial del recurso fiscal. Remesas para la defensa del puerto de Buenos Aires en el siglo XVII", Nuevo Mundo Mundos Nuevos (julio de 2016), consultado el 15 de diciembre de 2016. https://nuevomundo.revues.org/69317
} 
chilena, sino también a la relevante intervención de agentes privados en los mecanismos de regulación y gestión del situado chileno.

\section{La remisión del situado: sujeción de la Real Hacienda limeña a los mercaderes peruanos.}

Como se ha referido, el hecho de que el situado chileno se remitiese desde el virreinato, vino a significar que, en adelante, la defensa de Chile quedó subordinada a los excedentes generados a partir del rendimiento tributario de las cajas peruanas. Dicho de otra manera, el gasto situado en Chile quedó sujeto a las contingencias y eventualidades susceptibles de afectar a la real hacienda del Perú. Y esta circunstancia explica un hecho inequívoco: la imposibilidad argumentada por los virreyes de "acudir a todo con el contado", es decir, de pagar y enviar de una sola vez la suma de 292.729 pesos en dinero en efectivo con las "tantas cargas precisas que tiene (el virreinato)"26, propició que el situado chileno fuese remitido durante el siglo XVII, salvo el interregno en que se envió de Potosí ${ }^{27}$, en su mayor parte, en mercaderías, y que sólo una porción del mismo, en ocasiones bastante exigua, fuese consignada en moneda ${ }^{28}$. No obstante, a este razonamiento habría que sumar el reiterado conocimiento que las autoridades virreinales tenían acerca de que "en Chile no hay otra ropa que la que se lleva de Lima" ${ }^{29}$, y que vino a respaldar el perseverante procedimiento descrito.

En relación a lo anterior, y aplicando un juicio deductivo, los mercaderes de Lima pudieron ver en las plazas militares de la frontera chilena un mercado más hacia el que orientar sus actividades económicas. De hecho, y como han advertido ya algunos de los historiadores señalados, el simple examen de las cifras del situado chileno nos permite aventurar que una parte sustancial del mismo permaneció en la capital virreinal en manos de los acreedores peruanos, principalmente limeños. En teoría, la fórmula practicada consistió

\footnotetext{
${ }^{26}$ El virrey Melchor de Navarra y Rocafull al rey. Lima, 28 de noviembre de 1682. Archivo General de Indias (en adelante, AGI), Chile, 129.

${ }^{27}$ Entre 1690 y 1715 la remisión del real situado se hizo en moneda efectiva y directamente por tierra desde la caja real de Potosí.

${ }^{28}$ En contraposición del remitido en el mismo tiempo por la misma caja real a Panamá, efectuado íntegramente en moneda. Ver: Ramiro Alberto Flores Guzmán, "Los situados peruanos: desde Chile hasta Panamá, 17001800”, en El secreto del Imperio español..., 33-61.

${ }^{29}$ El virrey Melchor de Navarra y Rocafull al rey. Lima, 28 de noviembre de1682. AGI, Chile, 129.
} 
en difundir los requerimientos del ejército chileno mediante lectura o publicación de un bando público para que todos los mercaderes interesados tuviesen noticia. Y, en teoría, también, se alcanzaban los acuerdos con aquellos comerciantes que ofrecieran mayor calidad en los géneros y a los precios más corrientes en aquella ciudad. Sin embargo, estas apetencias fueron asiduamente objeto de denuncia por parte de las autoridades chilenas. Así, los géneros que conformaron la ayuda fueron con frecuencia de "tan mala calidad que son de aquellos que en lenguaje común de mercaderes llaman en bromas 'desechos de tiendas', que cuando no los tienen en las suyas los compran a otros a bajísimos precios para darlos al situado"30, mientras que la junta de real hacienda de Santiago hubo de resignarse a "que en la vigencia de la necesidad (estos géneros) se cometen sin elección" ${ }^{31}$.

Una lectura en profundidad de las datas de las cuentas de la caja de Lima nos permite conocer con precisión los artículos que se remitían a Chile como parte del situado, siendo la ropa de Castilla y de la tierra, los paños de Quito, las calcetas, los sombreros, las frazadas, las bayetas de Castilla, los tafetanes, los utensilios de hospital, las botijas de miel y aceite, así como diversos pertrechos para la guerra -como la pólvora y los floretes-, entre otros suministros, los más corrientes. El porcentaje de éstos en relación al capital monetario que integraba el situado chileno fue además en aumento a lo largo del siglo XVII. Al respecto, Vargas Cariola reveló que las mercaderías adquiridas en la capital virreinal absorbieron la mayor parte del situado hasta alcanzar valores aproximados al 60\% en la década de 1650, y casi el $80 \%$ del volumen total de la ayuda en las décadas de 1670 y $1680^{32}$, un progresivo aumento resultado de la creciente dificultad de la caja de Lima, sobre todo en las décadas finales del siglo, para satisfacer al contado el situado de Chile, y más particularmente, a la propia bajada de la producción de las minas argentíferas de Potosí ${ }^{33}$.

\footnotetext{
${ }^{30}$ Consulta de la junta de hacienda del situado al Consejo de Indias. Concepción, 8 de enero de1673. AGI, Chile, 129.

31 Acta de la Junta Superior de Real Hacienda. Santiago de Chile, 22 de julio de 1682. Archivo Nacional Histórico de Chile (en adelante, ANH), Junta Superior de Real Hacienda (en adelante, JRH), vol. 5, folios 2021.

${ }^{32}$ Vargas Cariola, "Financiamiento del ejército de Chile...", 182.

${ }^{33}$ Teniendo en cuenta que el situado estuvo subordinado a los excedentes generados a partir del rendimiento de la producción de la plata potosina, al declive de esta producción propició que la remisión del situado desde el Perú padeciera, en ocasiones, una merma de su caudal, retrasos en su llegada, o que, directamente, se quedaran debiendo.
} 
Siendo ineludible un estudio con mayor precisión sobre la evolución exacta de estas cifras a lo largo del siglo, podemos conferir algunos ejemplos para años concretos. Así, para el de 1640 los gastos situados en Chile desde la caja limeña fueron remitidos aproximadamente el $63 \%$ de ellos en mercancías, mientras que tan solo el $37 \%$ restante se remesaron en plata ${ }^{34}$. El porcentaje aumentó para el situado enviado en el año 1673, en el que aproximadamente el 68\% del total de la ayuda llegó a Concepción en mercancías, en contraste al $32 \%$ restante venido en moneda ${ }^{35}$. De igual forma, en 1680 llegaron a Chile los situados que se debían de los años 1678 y 1679, alcanzado el importe total de la conducción 584.558 pesos y 6 reales; de éstos, se remitieron en ropa y otros géneros la cantidad de 455.688 pesos (es decir, el 78\% de aquellos situados), siendo los 128.870 pesos restantes de la situación pagados en reales de contado (o lo que es lo mismo, el 22\% de los mismos remitido en plata $)^{36}$. Por su parte, en la década de 1680 , como se ha referido, las mercancías izaron aún más su porcentaje con respecto al capital en moneda; y así, tomando las cantidades aportadas por Marcello Carmagnani, el situado expedido en 1682 se completó en un 84\% en géneros, mientras que el arribado en 1687 -el último remitido en el siglo XVII desde Lima antes del cambio consignación a la caja de Potosí- alcanzó la ingente proporción en artículos del $94 \%{ }^{37}$.

Por otra parte, considerando las dificultades de la caja de Lima de pagar al contado los géneros que habrían de remitirse a Chile como parte del situado, los contratos suscritos con los mercaderes hubieron de refrendarse bajo el aval del crédito, por lo que en cada una de estas operaciones hubieron de concertarse y aplicarse las tasas de interés correspondientes $^{38}$. Teniendo en cuenta los crecidos intereses inherentes a la propia operación crediticia a la que se alude y que conllevó la subida del precio de las mercancías adquiridas a estos comerciantes sobre su valor ordinario en el mercado local limeño, esta

\footnotetext{
${ }^{34}$ Vargas, "Financiamiento del Ejército de Chile...", 189.

${ }^{35}$ Acta de la Junta Superior de Real Hacienda. Santiago de Chile, 6 de octubre de 1673. ANH, JRH, vol. 2, ff. 258-264.

${ }^{36}$ Real Cédula. Madrid, 13 de junio de 1681. AHN, Capitanía General (en adelante, CG), vol. 717, pieza 4, ff. 6-6v.

${ }^{37}$ Carmagnani, Los mecanismos de la vida económica..., 381-382.

${ }^{38}$ Considerando que la caja de Potosí actuó como intermediaria en la redistribución de los recursos fiscales, los comerciantes peruanos cobraban en Lima el valor de lo vendido una vez el dinero llegaba a la capital virreinal desde Potosí.
} 
circunstancia significó el inicio de un mecanismo de coacción por parte de los capitales privados sobre la real hacienda peruana en provecho de la ventajosa rentabilidad en sus operaciones. Dicho de otra forma, los mercaderes limeños pudieron manejar parte de la deuda pública del virreinato $\mathrm{y}$, en definitiva, contribuyeron a disminuir, en base a este procedimiento, el monto total de la ayuda señalada a las tropas chilenas de la frontera.

En efecto, la puesta en marcha del engranaje crediticio revalorizó en torno a un 20 o $30 \%$ el precio de los géneros negociados en Lima con los mercaderes peruanos; un interés que se mostró variable en base a las condiciones del mercado local en el momento de cada financiación. Nos remitimos a los testimonios compendiados en un sumario levantado por la real audiencia de Chile en $1682^{39}$ en relación a una real cédula del año anterior en la que se mandaba que los situadistas chilenos no recibiesen de otro modo el situado si no era en reales de contado, y que venía a adherirse al amplio inventario de despachos reales decretados de forma frustrada con el ideal de agotar los supuestos agravios que ocurrían en Lima con respecto al situado ${ }^{40}$. Dicho sumario incluye la averiguación que el tesorero de la real hacienda de Santiago, José Zorrilla de la Gándara, hizo acerca de los precios de los géneros que el situadista Fernando de la Llana trajo por cuenta del situado de 1682, considerando que éstos se encontraban crecidos alrededor de un $23 \%$ con respecto a lo pagado por artículos similares en la capital virreinal, y en la misma fecha, por algunos mercaderes de Concepción:

Dijo [el situadista] que en virtud de los poderes que tuvo del real ejército de este reino ocurrió a la ciudad de los Reyes a pedir el situado para la gente de guerra, y que por no haber habido plata en las reales cajas de la dicha ciudad para poderle entregar los 212.000 ducados de la situación que por los dos años que se debían importaban 420.000 ducados, fue preciso porque instaba el tiempo de su despacho antes que entrase el invierno tomar fiada la ropa que trajo por cuenta del dicho situado don José Blanco Rejón, mercader que la entregó a este testigo (...) $[y]$ que el cómputo que tiene hecho del valor y precio de los dichos géneros hay diferencia y exceso de $23 \%$ a los precios que por el mes de marzo del presente año tenían los dichos géneros en la dicha ciudad de los reyes comprados con los

\footnotetext{
${ }^{39}$ Testimonio del situadista Fernando de la Llana tomado por el tesorero José Zorrilla de la Gándara. Santiago de Chile, 23 de julio de1682. AGI, Chile, 129.

${ }^{40}$ Real Cédula de 22 de noviembre de 1646; Real Cédula de 18 de enero de 1650; Real Cédula de 26 de noviembre de 1668; Real Cédula de 31 de octubre de 1674; Real Cédula de 27 de marzo de 1776; Real Cédula de 24 de mayo de 1680; Real Cédula de 13 de junio de 1681; y, finalmente, Real Cédula de 16 de enero de 1687.
} 
reales de contado, y que el dicho exceso importa en todo el monto de los dichos géneros más de $54.000 \operatorname{pesos}^{41}$.

En la recopilación de antecedentes, el referido sumario integra también testimonios recogidos por el alcalde ordinario de la ciudad Concepción en 1673 -por orden del gobernador Juan Henríquez- sobre la misma materia. Así, aquél dispuso la comparecencia de los mercaderes locales Diego Pérez Moreno, Pedro de Fuentes y Pedro del Pozo y Silva, entre otros comerciantes "de experiencia en el manejo de los contratos" que se hallaban presentes en Lima en la compra de sus mercancías en el momento de entregarse los situados que se condujeron en 1671 y 1672 por los situadistas Juan Gutiérrez de Espejo y Mateo del Cajigal y Solar, de forma respectiva. Advirtió el mercader Diego Pérez con respecto a este último situado que "la ropa fue de muy mala calidad y en demasía cara", teniendo la certeza de ello por haberla visto "en los almacenes reales a donde fue llamado por los oficiales reales al tiempo y cuando los entregaban al dicho capitán Mateo del Solar”. En la misma línea, el comerciante Pedro de Fuentes informó que el exceso del precio de aquellos géneros superaba el $40 \%$ a pesar de constituir éstos "desechos de almacenes y de aquéllos que en Lima no tienen gasto"; y así, vio este testigo una partida de cuchillería, de bayetas de la tierra y de sombreros "de malísima calidad" que vinieron "por 18 reales siendo su precio en Lima 9 y 10 reales de buena calidad". Por su parte, Fernando del Pozo insistió en la mala calidad de la ropa comprada a los mercaderes peruanos en el situado que condujo Juan Gutiérrez de Espejo, y por la que se pagó un “30\% más de lo que este (testigo) declara la compró aquel año estando en la ciudad de los Reyes"42.

De igual forma, en otra real cédula de 1668 en la que la Corona ordenó al virrey la remisión del situado íntegramente en moneda efectiva, la reina regente Mariana de Austria, menos mesurada que los anteriores, dio cuenta de la práctica acostumbrada de dar la ayuda en mercancías “a precios tan excesivos que siempre llevan 50\% más del que se dan por ellos los que los compran al contado en esa ciudad"43. Al respecto, las autoridades chilenas levantaron en 1664 una memoria con los precios que hubieran tenidos los géneros que

\footnotetext{
${ }^{41}$ También en: Acta de la Junta Superior de Real Hacienda de Santiago. Santiago de Chile, 22 de agosto de 1682. ANH, JRH, vol. 5, ff. 20-21.

${ }^{4}$ Testimonios de Diego Pérez, Pedro de Fuentes y Fernando del Pozo tomados por el alcalde ordinario de primer voto de la ciudad de Concepción Alonso Barriga. Concepción, 13/14 de enero de 1673. AGI, Chile, 129.

${ }^{43}$ Real Cédula dirigida al virrey Conde de Lemos. Madrid, 26 de noviembre de1668. AGI, Chile, 36.
} 
integraron el situado llegado aquel año si se hubieran pagado en Lima al contado y a los precios corrientes en aquel mercado. En ella se descubrió cómo el crédito elevó 44.363 pesos y 5 reales el valor de los artículos remesados a Chile que, finalmente, alcanzaron una tasación de 172.000 pesos $^{44}$. Dicho de otra manera, el pago de intereses acrecentó un $35 \%$ el coste global de las mercancías que habrían de integrar el socorro situado para el sostenimiento de las guarniciones militares chilenas ${ }^{45}$.

De todo lo cual se desprende, en definitiva, la existencia de un mecanismo de dominación de la economía peruana sobre el situado de Chile al convertirse éste en garante del crédito; del productivo negocio de los mercaderes de Lima con respecto a la subvención chilena; y, como secuela evidente, la merma sustancial del capital numerario que finalmente llegaba a Concepción. Además, como los gastos situados para Chile viajaban, en su mayor parte, en mercancías, parece lógico pensar que los soldados recibirían su sueldo, también, en géneros, lo que llevó, como veremos a continuación, a la ejecución de transacciones no dinerarias que contribuyeron a turbar el ortodoxo objetivo de la ayuda.

\section{La confección del "mapa del pagamento" en Concepción: el pago "plata y ropa por mitad" y "creces" a las mercancías del Situado.}

Una vez arribaba el situado a Chile, se formaba una "junta de hacienda" -o "junta del situado"-, comisionada de confeccionar el llamado "mapa del pagamento". Es decir, la regulación del caudal a partir de la elaboración de un inventario o documento en el que se incluían las cargas y obligaciones del situado y a partir del cual fundamentar la posterior liquidación de lo adeudado, primero, con los acreedores del ejército en Concepción (los llamados "gastos forzosos") con el propósito de que no faltara "la confianza y buena fe de los empréstitos respecto de que si no se hiciese así cesarían los socorros"46; e, inmediatamente después, la retribución de los sueldos a los soldados que militaban en la frontera. Dicho de otra manera, después de deducir los gastos destinados a pagar a los mercaderes limeños en la

\footnotetext{
${ }^{44}$ Memoria de los géneros que trajo el situado de 1664 con los precios a que corrían en Lima comprándolos de contado. AGI, Chile, 103.

${ }^{45}$ Lamentablemente faltan las cuentas de la caja de Lima desde el 27 de abril de 1663 hasta la armada de 1664 (AGI, Contaduría, 1751). Su estudio nos habría permitido compulsar y establecer un exacto ejercicio comparativo.

${ }^{46}$ Instrucción para la distribución del situado. Madrid, 14 de abril de 1687. ANH, CG, Vol. 717, pieza 56, ff. 84-86v.
} 
capital virreinal, así como el propio importe de la conducción desde Lima a Concepción (los llamados “descuentos”), los responsables financieros del situado debían ajustar el caudal en plata y las mercancías recibidas para liquidar, por un lado, las cargas con los asentistas del ejército en Chile -principalmente proveedores de trigo, ganado y zapatos-; y, por otro, lo debido en concepto de sueldo a cada soldado.

En la coyuntura descrita, se hace preciso considerar dos aspectos. En primer lugar, dada la escasez de dinero líquido en las remesas situadas, unos y otros debieron ser pagados bajo la imprecisa fórmula "plata y ropa por mitad"; es decir, una parte en moneda y otra en mercancías. Pero además, en razón de lo menguado en que se encontraba el situado en este punto, insuficiente para abonar al mismo tiempo lo debitado al profuso contingente militar y a los acreedores privados, los agentes gestores de la ayuda hubieron de legalizar un arbitrario mecanismo basado en el reajuste falseado y al alza del importe de las mercancías que habrían utilizarse como medio de pago, sobre el valor, ya crecido de por sí, que traían desde Lima. Eran las llamadas “creces” a las mercancías del situado, que se constituyeron en el recurrente método empleado durante el siglo XVII para proporcionar los ingresos con los gastos.

Es decir, como lo remitido desde Perú no bastaba para el pago de los honorarios anuales de los soldados, a éstos se les entregaban los artículos limeños -en permuta de una buena parte de sus sueldos- a un costo aún mayor que el abonado por la Real Hacienda peruana a los mercaderes que habían avituallado durante el año al ejército. En la práctica, por tanto, el inicuo mecanismo conllevó una camuflada minoración de los salarios concertados a los soldados en base al supuesto desconocimiento por parte de éstos acerca de los precios de mercado en el año preciso de la distribución. De esta última circunstancia dio cuenta Pedro Fernández de Moreda, visitador de las cajas de Chile en 1682 por comisión especial del virrey Duque de la Palata, al informar que "nunca saben éstos (los soldados) lo que les dan porque no tienen noticia del valor a que viene de Lima el género", de manera que, a pesar de lo regulado, "unos años les tocará más o menos según la bondad del situado y menos pagas que tuviera contraídas el ejército" 47 .

\footnotetext{
${ }^{47}$ Consulta del visitador Pedro Fernández de Moreda al gobernador José de Garro, Concepción, 12 de octubre de 1682. AGI, Chile, 129.
} 
Ya desde un principio se hizo constar como las directrices marcadas por la Corona sobre esta materia hubieron de ser objeto de negociación entre los agentes del poder gestores de la ayuda -local y virreinal-, y las autoridades superiores en la metrópoli. Así, si en 1609 el monarca Felipe III, temprano conocedor de que se gravaba "la ropa que se lleva para la gente de guerra de ese reino a razón de $25 \%$ sobre lo que cuesta en el Perú", mandó que, en adelante, "no se cargue más de solamente la costa que la dicha ropa tiene hasta llevarla y ponerla donde se entregue a los soldados" ${ }^{\prime 4}$, su sucesor en el trono, Felipe IV, volviendo a advertir en 1649 la práctica acostumbrada de "crecer el precio de la ropa" de forma abusiva, se resignó a preceptuar, no obstante, “que de ninguna manera se hiciese creces al precio de la ropa al más de $10 \% " 49$.

De la misma forma, si bien otra real cédula del mismo monarca fechada en 1662 y dirigida al gobernador de Chile, Ángel de Peredo, mandaba entonces que no se permitiera “que se den a los soldados (las mercancías) a más valor de aquel que estuviesen puestos en esas provincias (de Lima)", con objeto de que de esta forma no se hiciese "perjuicio a los soldados por lo que importa conservarlos y mantenerlos" ${ }^{\prime 50}$, dando cuenta, además, de haber advertido de ello al virrey del Perú, éste último, no obstante, recusó al monarca en los términos que siguen dando cuenta, en definitiva, de la ductilidad en la aplicación de la ley derivada de las particulares circunstancias que, en la práctica, obstaculizaron su implacable ejecución:

Aunque en Cédula particular para el reino de Chile tiene V. M. ordenado que no se echen creces a la ropa que se distribuye en el ejército, no ha sido posible ejecutar esta orden porque como la situación es determinada de 212.000 ducados en cada año, si son mayores los empeños y gastos del situado, es preciso acrecentar el precio de la ropa para que en prorrata les quepa a todos con igualdad $^{51}$.

En la "Recopilación de las Leyes de Indias" de 1680 se volvió a reiterar "que a los soldados no se les cargue la ropa a más del costo principal”"52, una disposición que, por su

\footnotetext{
${ }^{48}$ Real Cédula. Madrid, 5 de julio de 1609. Manuscritos Medina (en adelante, MM), tomo 272, doc. 7859 , ff. 27-29.

${ }^{49}$ Real Cédula. Aranjuez, 29 de abril de 1649. MM, tomo 272, doc. 7971, ff. 193-194.

${ }^{50}$ Real Cédula. Madrid, 9 de abril de 1662. ANH, CG, vol. 715, pieza 45, ff. 87-88.

${ }^{51}$ Carta del virrey Conde de Santiesteban al rey. Lima, 20 de noviembre de 1662. MM, tomo 232, doc. 6093, ff. 74-77.

${ }^{52}$ Recopilación de las Leyes de los Reinos de Indias (en adelante, RLI), libro III, título XII, ley X.
} 
propia redundancia, da muestra de la persistente inobservancia de la norma dictada. Volviéndola a eludir, sin embargo, la junta superior de real hacienda de Santiago reconoció, dos años después, la ineludible exigencia de "cebarle exorbitantes crecimientos" al valor de las mercancías entregadas al ejército "por haber de igualar sus empeños"53. Es decir, la conveniente necesidad de aplicar una vía para equilibrar, a partir de la subida adulterada del coste de los géneros recibidos, los exiguos ingresos del situado con los inexcusables gastos inherentes a la actividad militar. Puede decirse, en suma, que las creces que se imprimieron al valor de las mercancías persistieron ininterrumpidamente a lo largo de todo el siglo XVII sin que el "fraude y engaño con que se procedía en los pagamentos de los situados por espacio de tantos años, como así ha ocurrido sin contravención de lo dispuesto por cédulas de $\mathrm{Su}$ Majestad"54, tal y como advirtió el gobernador José de Garro en 1682, experimentase alteración alguna.

Por otra parte, en cuanto al porcentaje sobrepuesto a los crecimientos, sabemos que en la primera década del siglo XVII éstos alcanzaron ya el $25 \%{ }^{55}$, adquiriendo valores mucho mayores a medida que las mercancías adquiridas en Lima fueron integrando la mayor parte del situado. Por un razonamiento deductivo, cuanto mayor fue la cantidad de géneros remesados desde Perú, mayor fue la exigencia de recurrir a la práctica de aplicar creces al valor de estos productos en Chile. Al respecto, el gobernador Juan Henríquez reconoció, a principios de la década de 1670, la exigencia de "echarle a la ropa de crecer un $70 \mathrm{u} 80 \%$ " 56 . Por su parte, el referido visitador Pedro Fernández de Moreda certificó a principios de la década siguiente "que hay géneros que tienen sobre el costo de Lima 75-80\% y otros menos que no bajan de 53\%"57, a la vez que el gobernador José de Garro, reconociendo "el fraude y el engaño con que se procedía", admitía no poder "socorrer al ejército y pagar las libranzas

\footnotetext{
${ }^{53}$ Acuerdo de la Junta Superior de Real Hacienda de Santiago. Santiago de Chile, 22 de julio de 1682. ANH, JRH, vol. 5, ff. 101-106.

${ }^{54}$ El gobernador José de Garro al rey. Concepción, 13 de octubre de 1682. MM, Tomo 166, Doc. 3417, ff. 249253.

${ }^{55}$ Real Cédula. Madrid, 5 de agosto de 1609. ANH, Fondo Antiguo (en adelante, FA), vol. 715.

${ }^{56}$ Vargas, "Financiamiento del ejército de Chile...", 190.

${ }^{57}$ Consulta del visitador Pedro Fernández de Moreda al gobernador José de Garro, Concepción, 12 de octubre de 1682. AGI, Chile, 129.
} 
acordadas sin echar un $53 \%$ por ciento a la ropa que trajo el situado de más de los precios de Lima" ${ }^{\circ 8}$.

De igual forma, los capitanes Mateo del Cajigal y Solar y Francisco de Puga y Novoa, tesorero y contador respectivamente de las reales cajas de Concepción, dieron cuenta en 1684 de la puntualizada costumbre de gravar "la ropa a más de un $50 \%$ cada año sobre los precios que traía"59, mientras que el fiscal de la real audiencia, Pablo Vázquez de Velasco, menos comedido que los anteriores, testificó al monarca en 1690 que cuando el situado venía en mercancías se consignaban "tales creces al valor de la ropa que a los géneros que venía en la carta cuenta de Lima les subían un 100 y $200 \%$ de valor poniendo en todos precios fantásticos" ${ }^{\prime 60}$.

Considerando todo lo reseñado, y basándonos en la información aportada por Vargas Cariola, el situado remitido en 1640 llegó a Concepción restringido a 224.957 pesos - de los cuales 125.511 vinieron en mercancías $(55,79 \%)$ y 99.446 en plata $(44,21 \%)$-, cuando el monto total adeudado con acreedores y soldados alcanzaba los 312.767 pesos $^{61}$. Al respecto, sólo imponiendo artificialmente exorbitantes crecimientos a los géneros que se entregaron a los soldados en aquella distribución, pudieron las autoridades competentes cancelar parte de las deudas comprometidas con éstos. En el mismo sentido, para el situado que llegó en 1678 de 212.000 ducados fue necesario "dar crecimiento a la ropa como se ha acostumbrado para igualar a los dichos empeños y gastos precisos", superiores éstos a la cantidad remesada desde Lima, "para el pagamento de las 2.000 plazas situadas", de manera que sólo imponiendo "creces" a los géneros logró hacerse "caudal de 387.487 pesos" con el que pudo satisfacerse "la distribución del real situado según el dicho cómputo"62. Lo que certifica, además, que el situado, en definitiva, aunque se desembolsara íntegro desde Lima, limitadamente bastaba para satisfacer el pago de las deudas comprometidas por el ejército,

\footnotetext{
${ }^{58}$ El gobernador José de Garro al rey. Concepción, 13 de octubre de 1682. MM, tomo 166, doc. 3417, ff. 249253.

${ }^{59}$ Los oficiales reales de Concepción al rey. Concepción, 15 de enero de 1684. MM, tomo 167, doc. 3437, ff. 24-28.

${ }^{60}$ El fiscal de la real audiencia Pablo Vázquez de Velasco al rey. Santiago de Chile, 25 de septiembre de 1690. MM, tomo 168, doc. 3483, ff. 37-57v.

${ }^{61}$ Vargas, "Financiamiento del ejército de Chile...", 189.

${ }^{62}$ Acuerdo de la Junta Superior de Real Hacienda de Santiago. Santiago de Chile, 13 de agosto de 1678. ANH, JRH, vol. 5, ff. 20-21.
} 
circunstancia que en palabras del tesorero José Zorrilla de la Gándara y del procurador del ejército Pedro Sebastián de Zaldías, se descubre con una perspicuidad definitiva:

No alcanza la porción del situado con más de cien mil pesos [esto es, aumentando por esta última cantidad el valor estipulado del situado de Chile] a lo que se necesita para el entero de sueldo y gastos, y para que llegue a dicha cantidad cargan de creces a la ropa aquella cantidad que falta, con que al soldado que habían de dar la vara de paño de Quito por 3 pesos que es a como valdría en esta ciudad, se la entregan cargada a 4 pesos y 4 reales, y así en los demás géneros ${ }^{63}$.

Otro ejemplo. En la junta de Real Hacienda celebrada en Santiago el 6 de octubre de $1673^{64}$, el gobernador Juan Henríquez, considerando que "era corto el caudal que había”, propuso "acrecentar los precios de la ropa y de empeños sobre los de su costo en Lima en la forma que se ha acostumbrado en todos los antecedentes" para la distribución que habría de hacerse del situado en Concepción, certificando, en suma, lo habitual de la práctica descrita. En concreto, consumados los descuentos en la capital virreinal -que alcanzaron 41.350 pesos y 6 reales-, el situado llegado a Concepción fue de 250.928 pesos y 5 reales, de los cuales aproximadamente el 68\% llegó en ropa y otros géneros (por valor de 171.118 pesos), y el $32 \%$ restante en moneda (79.810 pesos y 5 reales). En aquel año, sin embargo, sólo "para la paga y el socorro de 2.141 plazas que hay efectivas y se han de socorrer", se requirieron 237.100 pesos y 6 reales, cantidad a la que se hubo de adicionar 133.452 pesos y 7 reales en concepto de "gastos forzosos" comprometidos con los acreedores del ejército en Chile. Es decir, la deuda final del ejército se fijó en 370.553 pesos y 3 reales ${ }^{65}$, reconociéndose un desfase con respecto a lo remitido desde Lima de 119.625 pesos y 2 reales. [Tabla 1].

\section{REAL SITUADO RECIBIDO EN CONCEPCIÓN EN 1673}

\begin{tabular}{|c|c|c|c|c|}
\hline Situado rem & desde la caja de & & \multicolumn{2}{|c|}{292.279 pesos y 3 reales } \\
\hline Descuentos & & & \multicolumn{2}{|c|}{41.350 pesos y 6 reales } \\
\hline \multirow{3}{*}{ SITUADO } & \multirow{3}{*}{ RECIBIDO } & \multirow{3}{*}{$\mathbf{E N}$} & \multicolumn{2}{|c|}{250.928 pesos y 5 reales } \\
\hline & & & En mercancías & En moneda \\
\hline & & & 171.118 pesos $(68 \%)$ & 79.810 pesos y 5 \\
\hline
\end{tabular}

${ }^{63}$ Informe de José Zorrilla de la Gándara y Pedro Sebastián de Zaldías al rey. Concepción, 15 de noviembre de 1682. MM, tomo 166, doc. 3422, ff. 264-279.

${ }^{64}$ Acuerdo de la Junta Superior de Real Hacienda de Santiago. Santiago de Chile, 6 de octubre de 1673. ANH, JRH, vol. 2. ff. 258-264.

${ }^{65}$ En realidad, la deuda total de aquel situado fue de 370.553 pesos y 5 reales. La diferencia de dos reales se debe a que los responsables financieros sumaron los gastos comprometidos con los acreedores (133.452 pesos y 7 reales) y los gastos relativos a los sueldos de los soldados (237.100 pesos y 6 reales) como fracciones, no aplicando la equivalencia 1 peso $=8$ reales. 


\section{DEUDAS DE LA REAL HACIENDA DEL SITUADO}

\begin{tabular}{|l|c|c|}
\hline Sueldos de los soldados & 237.100 pesos y 6 & $64 \%$ del déficit \\
\hline Gastos forzosos & 133.452 pesos y 7 & $36 \%$ del déficit \\
\hline DEUDA TOTAL & \multicolumn{2}{|c|}{370.553 pesos y 3 reales } \\
\hline DÉFICIT & 119.625 pesos y 2 & $33,28 \%$ \\
\hline
\end{tabular}

Tabla 1. Esquema general del mapa del pagamento del real situado remitido en 1673 (I). [Elaboración propia, ANH, JRH, vol. 2. ff. 258-264].

En aquella junta de hacienda se acordó que de lo debitado a los soldados, el $88 \%$ se liquidaría en ropa y otros géneros remitidos desde Lima mientras que el 12\% restante se les retribuiría en dinero en efectivo. De igual forma, recurriendo a la fórmula "plata y ropa por mitad" con mayor rigor, lo adeudado con los acreedores privados que habían abastecido al ejército habría de satisfacerse, según lo convenido, el 53,12\% en mercancías y el 46,88\% en moneda. En resumen, de la deuda total contraída por el ejército se acordó que el 75,5\% de la misma se saldase en mercancías. Y habiéndose referido la materia y aceptada la coyuntura por los presentes, la Junta resolvió que "se proporcionase con la mayor satisfacción lo forzoso de las pagas con el aumento de los dichos precios" con objeto de equilibrar la entrada de las mercancías vía situado (según lo referido, ropa y otros géneros por valor de 171.118 pesos), con las deudas que habrían de saldarse con ellas (a saber, 279.532 pesos y 6 reales). Es decir, había que dar crecimiento a las mercancías que se iban a utilizar como "moneda" de pago por valor de 108.414 pesos. [Tabla 2].

\begin{tabular}{|l|c|}
\hline \multicolumn{2}{|c|}{ DEUDA A SATISFACER EN MONEDA } \\
\hline Moneda remitida desde Lima & 79.810 pesos y 5 reales \\
\hline Sueldo de los soldados & 28.458 pesos y 6 reales $(12 \%$ del sueldo) \\
\hline Gastos forzosos & 62.562 pesos y 1 real $(46,88 \%$ del pago a los \\
\hline DEUDA TOTAL & 91.020 pesos y 5 reales \\
\hline DÉFICIT & 11.210 pesos \\
\hline \multicolumn{2}{|c|}{ DEUDA A SATISFACER EN MERCANCÍAS } \\
\hline Mercancía remitida desde Lima & 171.118 pesos \\
\hline Sueldo de los soldados & 208.642 pesos y 6 reales $(88 \%$ del sueldo $)$ \\
\hline Gastos forzosos & 70.890 pesos y 6 reales $(53,12 \%$ del pago a los \\
\hline DEUDA TOTAL & 279.532 pesos y 6 reales \\
\hline DÉFICIT & 108.414 pesos \\
\hline
\end{tabular}


Tabla 2. Esquema del mapa del pagamento del real situado remitido en 1673 (II): satisfacción de las deudas contraídas con los soldados y con los acreedores del ejército. [Elaboración propia, ANH, JRH, vol. 2. ff. 258-264].

Así, entre otros géneros, una partida de 18.000 varas de bayetas de la tierra que fue adquirida a los comerciantes peruanos a 5 reales la vara, fue tasada para su venta en Concepción a 9 reales; 150 azadones que costaron en la capital virreinal a 6 pesos y 4 reales cada uno, se tasaron a 9; 20 botijuelas de aceite compradas a 20 reales, fueron valoradas a 5 pesos (40 reales); 225 libras de añil que costaron a 14 reales, se justipreciaron a 20; 1.999 varas de telas bretañas que se compraron a 7 reales y medio, se tasaron a 2 pesos (16 reales); otra partida de 785 varas y media de bayetas de la tierra que costaron a 3 pesos en Lima, se tasó a 6 pesos la vara en Concepción; 800 libras de cera labrada que se compraron a 12 reales, se tasaron para su venta al ejército a 20 pesos (es decir, a 160 reales); mientras que 32.856 varas de ruan florete que se adquirieron a 10 reales y medio, se pusieron en venta en la frontera a 16 reales $^{66}$.

En suma, las creces aplicadas a la mayor parte de los productos llegados de Lima como parte del situado incrementaron el valor de los mismos en 104.411 pesos y 3 reales -hasta alcanzar los 276.529 pesos y 3 reales-, o lo que es lo mismo, un acrecentamiento medio del $61 \%$ con respecto al ya elevado importe de venta cargado por los comerciantes peruanos. En cualquier caso, como lo adeudado en mercancías con los acreedores del ejército y soldados era, como se dijo, de 279.532 pesos y 6 reales, aún se quedaron debiendo 3.003 pesos y 3 reales "por no poderse acrecentar más los precios”, de manera que aquella junta de hacienda, de común acuerdo, autorizó al gobernador a "disponer del entero de la forma en que su señoría fuese servido" 67 . [Tabla 3].

\begin{tabular}{|l|c|}
\hline \multicolumn{2}{|c|}{ APLICACIÓN DE CRECES A LAS MERCANCÍAS DEL SITUADO } \\
\hline Crecimiento a las mercancías & $\mathbf{1 0 4 . 4 1 1}$ pesos y 3 reales $(61 \%)$ \\
\hline Valor de las mercancías tras las creces & 276.529 pesos y 3 reales \\
\hline DÉFICIT & 3.003 pesos y 3 reales \\
\hline \multicolumn{2}{|c|}{ DÉFICIT TOTAL FINAL } \\
\hline
\end{tabular}

\footnotetext{
${ }^{66}$ Todos los géneros han sido contrastados con las cuentas de la caja de Lima para dicho año (AGI, Contaduría, 1755).

${ }^{67}$ Acuerdo de la Junta Superior de Real Hacienda de Santiago. Santiago de Chile, 6 de octubre de 1673. ANH, JRH, vol. 2. ff. 258-264.
} 


\begin{tabular}{|l|c|}
\hline En moneda & 11.210 pesos \\
\hline En mercancías & 3.003 pesos y 3 reales \\
\hline DÉFICIT TOTAL & 14.213 pesos y 3 reales \\
\hline
\end{tabular}

Tabla 3. Esquema del mapa del pagamento del real situado remitido en 1673 (III): creces y déficit final.

[Elaboración propia, ANH, JRH, vol. 2. ff. 258-264].

\section{Liquidación de "gastos forzosos" y el pago a los soldados: desajustes especulativos en los términos de intercambio en perjuicio de la tropa.}

Del ejemplo anterior se puede discurrir, además, cómo los compromisos de pago del ejército con los proveedores de alimentos y otras mercancías en Concepción, fueron formalizados por la junta de hacienda de igual modo que se satisfacía el salario de los soldados. Es decir, en base a la referida fórmula "plata y ropa por mitad" -no siempre aplicada, como se ha visto, de forma literal, y en evidente sujeción a la proporción de reales de contado realmente consignados desde Lima-, el pagamento a los acreedores chilenos se liquidó, parte con dinero en efectivo y otra considerable fracción en géneros remitidos por los mercaderes limeños, fundamentalmente ropa. Unos géneros que, por otra parte, habrían de servirles para disponerlos nuevamente en un mercado caracterizado, precisamente, por la exigua producción de dichos productos.

La situación descrita derivó en otra circunstancia igualmente perniciosa para los soldados que servían en el real ejército de la frontera. Así, siendo sabedores de que parte de los géneros llegados de Lima se iban a convertir en moneda de cambio de sus productos; que la tasación de aquellas mercancías proveídas por los mercaderes peruanos superaban el precio de mercado en el momento de su provisión en la capital virreinal; y que la constante parvedad de los situados impelía continuamente a las autoridades financieras competentes en Concepción a imponer crecientes y simulados precios al valor de los mencionados bienes de cambio importados desde Perú, los acreedores chilenos arbitraron también incrementar de forma adulterada el coste de los artículos refrendados en sus asientos con el ejército sobre el precio natural que aquéllos tenían en el mercado consumidor de Concepción. 
Expuesta la coyuntura de otra forma, los hacendados y estancieros en Chile hicieron mímesis de forma anticipada del proceder de la junta de hacienda, alzando artificialmente el precio de los productos que iban a vender al ejército y que terminaron por acrecentar, de esta forma, los "gastos forzosos" que la institución militar habría de satisfacer cada año con ellos. De lo que se concluye que, al igual que ocurría con los mercaderes peruanos, la clase comerciante chilena controló, igualmente, parte de la deuda pública de la Real Hacienda de Concepción y la liquidez en el mercado local, favoreciéndose, en este sentido, de una notable fracción del flujo de caudales llegados por la vía del situado.

A este respecto, en el apuntado informe redactado por José Zorrilla de la Gándara y Pedro Sebastián Zaldías en 1682, los firmantes aseguraron que "el vecino (acreedor) que vende el trigo, sabiendo que en los géneros con que se le pagan le cargan un 50\%", éste, a su vez, justipreciaba el cereal destinado al ejército a "más de un $80 \%$ " sobre el valor de mercado en Concepción, de forma que pudiera asegurarse un rendimiento favorable en la transacción. Así, si en aquel año el trigo costaba de "9 a 10 reales fanega en aquella ciudad," el asentista del grano, sabiendo que sería abonado por la junta de hacienda del situado "mitad en plata y mitad en ropa”, y que ésta última vendría gravada de antemano de la forma ya descrita, se lo vendía al ejército a 20 reales la fanega, de manera que "si en los 10 reales de la ropa (valor al que se compró en Lima) granjea el ejército 3 reales y 1/2 (aplicando creces), el vecino en el trigo le damnifica en 10 reales" con que preservarse de quedar en quebranto ${ }^{68}$. Una situación que dio lugar, en definitiva, a un desequilibrio económico basado en la pérdida del valor real de los términos de intercambio en Concepción y, aún más relevante, a la disminución del poder adquisitivo de los soldados, que por el valor del sueldo que se les asignaba, percibirían, en suma, menor cantidad de bienes de inexcusable consumo. Esto supuso, en definitiva, que el trigo, la carne o los zapatos que se les entregaban a los soldados en Concepción estuvieran también sujetos a inicuas “creces” implementadas directamente, ahora, por los acreedores en Chile, y que en la práctica no hicieron sino disminuir, aún más, sus ya mermadas retribuciones.

\footnotetext{
${ }^{68}$ Informe de José Zorrilla de la Gándara y Pedro Sebastián de Zaldías al rey. Concepción, 15 de noviembre de 1682. MM, tomo 166, doc. 3422, ff. 264-279.
} 
En teoría, los sueldos militares establecidos por el Rey Felipe III en la real cédula de 20 de marzo de 1607, perseveraron inmutables a lo largo del siglo XVII ${ }^{69}$. En la práctica, no obstante, el soldado recibió un ingreso anual al contado considerablemente muy inferior a lo reglamentado (en el ejemplo se descubrió cómo tan solo el 12\% de sus sueldos se iba a satisfacer en moneda), que vino a coincidir con dos circunstancias conexas: en primer lugar, los referidos crecimientos al valor de las mercancías que se les adjudicaban como parte de sus sueldos, tanto las suministradas desde Lima como a las avitualladas en Chile; y, en segundo lugar, el aumento congruente de los precios de los géneros y alimentos dispuestos para ser comprados por los soldados con la moneda efectiva con la que habían visto satisfecha una parte de su remuneración. En última instancia, si el ingreso monetario del soldado se redujo a lo largo de todo el periodo estudiado en las formas referidas, a la vez que aumentaba el nivel de los precios de los productos a ellos destinados, se puede concluir que con cada unidad de moneda los soldados pudieron adquirir, en diferente magnitud a lo largo del siglo, menor cantidad de bienes, viendo de esta manera despreciado, en definitiva, su poder de compra:

Este motivo fuera de otro que representar a V.M. me obligaron a darle cuenta de los abusos que hallé introducidos sobre este punto, pues siendo así que esta situación se compone de 212.000 ducados al año y que según el placerte los soldados de Arauco tenían señalados 132 pesos y 4 reales al año, y solamente les daban al tiempo del pagamento 70 pesos, incluso un 50\% y otras veces 60 o $70 \%$ de más del precio que costó el género en Lima, llega a suceder no recibir el milite soldado de a caballo 35 pesos de valor intrínseco. Y lo mismo un soldado infante que tiene señalados 105 pesos al año y le dan 60 con creces, sucede no recibir realmente valor de 30 sin ellos. Y a este respecto los demás de este ejército según la proporción de sus sueldos ${ }^{70}$.

En síntesis, todo el proceso descrito convirtió en ficticio y aparente el pagamento a los soldados y posibilitó la puesta en marcha de un doble mecanismo de rentabilidad fiscal para la élite comercial y militar de Concepción. Así, en primer lugar, si las creces a los precios de la ropa y alimentos propiciaron que los soldados recibiesen menor cantidad de estos géneros por el valor concertado de sus sueldos -insuficientes en todo caso para avalar su

\footnotetext{
${ }^{69}$ Entre otras remuneraciones, y constituyendo la base del plan presupuestario, los soldados de infantería habrían de percibir 105 pesos anuales, mientras que a los soldados de caballería habría de corresponderle 132 pesos en el mismo periodo de tiempo.

${ }^{70}$ Consulta del visitador Pedro Fernández de Moreda al gobernador José de Garro, Concepción, 12 de octubre de 1682. AGI, Chile, 129.
} 
supervivencia-, parece lógico que éstos tuviesen que afluir al mercado de Concepción para avituallarse. Esto supuso que la retribución en moneda al contado traspasada a los soldados pasase a integrar, en última instancia, las arcas privadas de los acreedores del ejército en Chile, que se salvaguardaban de cobrar en metálico la venta de unos géneros que con dificultad hubieran logrado a través del comercio ordinario en la región o en sus propias tiendas.

Y, en segundo lugar, en el marco del contexto inflacionario descrito -a lo que habría que añadir la frecuente demora en la llegada de los situados e, incluso, la existencia de remesas que por diferentes razones llegaron incompletas-, los soldados, con lo poco que alcanzaban a comprar, y desprovistos de proporcionados ingresos, hubieron de recurrir frecuentemente a adelantos a crédito de géneros y alimentos que fueron provistos por los acreedores locales o por la misma oficialidad militar. Se reproduce, en resumen, el mecanismo subsidiario de financiación controlado por las élites locales, ya no ligada directamente a la Real Hacienda del situado, sino encauzados, ahora, a una tropa falta de recursos con los que sustentar su propio consumo. En consecuencia, el sistema propició un mecanismo de endeudamiento de los soldados a cuenta del situado, contenedor inclusive, en ocasiones, de un automatismo de crecimiento que gestó una última secuela: que a la llegada del siguiente situado, la caja real liquidara la deuda particular de los soldados con los acreedores que acudían con libranzas en perjuicio de los sueldos a ellos destinados ${ }^{71}$. Atendiendo a esta situación, en definitiva, se comprenden las desoladoras y abundantes descripciones acerca de la desnutrición, la desnudez y extenuación de los soldados que servían en la frontera chilena a lo largo del siglo XVII.

En esta coyuntura, no faltaron quienes tratando de resolver el problema que significaba que el real situado viniera desde Lima en mercancías adquiridas en operaciones a crédito -y con ello, con una tasación superior al precio de mercado en la capital virreinal-; lo que determinaba, a su vez, la imposibilidad de satisfacer en Chile los gastos forzosos comprometidos con acreedores y soldados; y, en última instancia, la exigencia de cargar de forma desmedida los precios del vestuario y los alimentos que se entregaban a éstos últimos

\footnotetext{
${ }^{71}$ La circunstancia descrita no es, ni mucho menos, privativa del situado chileno; por el contrario, se repitió en otras demarcaciones territoriales de América que también contaron con Situados. Al respecto, ver por ejemplo: Martin L. E. Wasserman, "Real Situado y gestión patrimonial del recurso fiscal...".
} 
como estrategia para equilibrar las entradas con los gastos; determinaron informar al monarca, y a su Consejo de Indias, de la conveniencia de que el socorro retribuido desde Perú fuese remitido íntegro en moneda acuñada directamente desde la caja real de Potosí. Al respecto, por acuerdo de junta de Real Hacienda de Santiago suscrito el 22 de julio de 1682 sus integrantes "fueron de parecer que sería conveniente que su majestad que Dios guarde mandase que los 212.000 ducados de la situación del ejército de este reino se pagasen en la caja de Potosí"72, de la misma forma que, unos días después, el gobernador José de Garro, solicitando al monarca el mismo cambio de consignación de la caja expedidora, vaticinó al rey que con el patrocinio de aquella medida la distribución del situado habría de efectuarse “con más igualdad sin necesidad de buscar medios de proporción en el crecimiento del valor de la ropa y en la calidad de ella"73.

En el mismo sentido, incidiendo de nuevo en los "daños que padece el ejército en la forma con que se hacen los despachos de los situados" y en las creces con que se cargaba la ropa y el alimento de los soldados, Zorrilla de la Gándara y Sebastián de Zaldías aseveraron al monarca que estos menoscabos persistirían siempre que el situado no llegase íntegro en plata, "lo cual no se conseguirá sino sirviéndose V. M. de quitar la consignación de dicha situación de estas cajas de Lima pasándola a la de Potosí”. Por último, Diego Cristóbal Mesía, oidor de la real audiencia de Lima, un año antes de remesarse el primer situado desde Potosí, consideraba que como secuela del cambio de adjudicación y "por el beneficio de no desfalcarles en ellos (los situados) lo que subían los precios de las mercaderías que se les repartían (a los soldados)", de forma inequívoca habrían de declinar "los precios de la harina, pan y zapatos que se les dan y anticipan”, sopesando la posibilidad en la inédita coyuntura de "ahorrar y dejar alguna parte (del situado) en las cajas reales a beneficio de la real hacienda" ${ }^{74}$. La medida suplicada desde Chile y ordenada por Carlos II en $1687^{75}$, mejoró poco o nada, sin embargo, la desdicha del soldado chileno; por el contrario, como testimonió

\footnotetext{
${ }^{72}$ Acuerdo de la Junta Superior de Real Hacienda de Santiago. Santiago de Chile, 22 de julio de 1682. ANH, JRH, vol. 5, ff. 101-106.

${ }^{73}$ El gobernador José de Garro al rey. Santiago de Chile, 26 de julio de 1682. MM, Tomo 166, doc. 3415, ff. 227-240.

${ }^{74}$ Diego Cristóbal Mesía al rey. Potosí, 20 de enero de 1689. MM, tomo 167, doc. 3476, ff. 315-321.

${ }^{75}$ Real Cédula de El Pardo, 16 de enero de 1687. ANH, CG, vol. 717, pieza 56, ff. 82-87.
} 
el cronista Vicente Carvallo y Goyeneche en su Descripción histórico y geográfica del Reino de Chile (1796), "lejos de extinguir el mal, aumentó la enfermedad"76.

\section{Consideraciones finales.}

La lejanía de Chile con respecto a la metrópoli, su aislamiento dentro del propio contexto americano y, en última instancia, el desconocimiento de las particularidades políticas y económicas del reino, propiciaron que las directrices marcadas por la corona sobre diferentes materias reguladoras del real situado hubieran de ser continuamente objeto de tensión y negociación entre los agentes del poder indianos administradores de la ayuda, los agentes privados y las propias autoridades metropolitanas. Así, el amplio inventario de despachos que ordenaban, entre otras cosas, que el situado fuese enviado íntegramente en moneda y no en mercancías -como en la práctica sucedió por las razones expuestas-, o que dichas mercancías no fuesen gravadas con "creces" con respecto a su valor real -siendo en la praxis, no obstante, como se ha visto, la vía que los responsables financieros del situado aplicaron para proporcionar los ingresos con los ingentes y superiores gastos-, revelaron, por su reiteración a lo largo del siglo XVII, la perseverante desobediencia de las directrices reales impuestas al respecto, y la adopción, en la práctica, y bajo el conocimiento y resignación de la metrópoli, de procedimientos antagónicos que dieron respuesta a la realidad precisa.

Así, a las comodidades financieras ofrecidas por los capitales privados peruanos a la real hacienda de Lima, adelantando sus productos en operaciones crediticias en base a la supuesta capacidad de la hacienda real peruana para hacer frente a los pagos a corto plazo, se adicionaron, también, las posibilidades de endeudamiento de la caja de Concepción con hacendados y estancieros chilenos en función del teórico capital entrante, en mercancías y en moneda, vía situado. En definitiva, el situado acabó convertido en base y garantía del crédito. Esto implicó, en suma, el establecimiento de una forzosa sujeción económica de las haciendas reales implicadas en la tutela y administración de la deuda imperial en torno al situado con respecto a los capitales privados que, en la práctica, ejercieron un inflexible control del flujo de caudales procedentes de esta ayuda, de la que fueron, también, sus principales adjudicatarios. En efecto, como han sostenido Alejandra Irigoin y Regina Grafe en recientes

\footnotetext{
${ }^{76}$ Vicente Carvallo y Goyeneche, Descripción histórico y geográfica del Reino de Chile, tomo III, capítulo 60 (Manuscrito, Biblioteca Nacional de Chile).
} 
estudios, sectores sociales privilegiados -en nuestro caso particular, mercaderes de Lima y Chile- se sirvieron de este sistema de transferencias fiscales a la frontera chilena para obtener réditos particulares. En todo caso, somos conocedores de la necesidad de efectuar un análisis de mayor profundidad acerca de estos grupos de agentes privados en el sistema de financiación militar chileno y, sobre todo, de la influencia real que profesaron en las áreas económicas en la que se desenvolvieron.

Por otra parte, que desde Lima se dispusiera que el real situado de Chile se enviase, parte de él, en mercancías, llevó implícito que en la gestión y distribución de la ayuda en Concepción se registrasen operaciones no monetarias que terminaron por perturbar el legítimo sentido de la ayuda. La preceptiva liquidación de lo adeudado por parte de los responsables financieros del situado en la referida fórmula "plata y ropa por mitad” propició, en este sentido, la puesta en marcha de un mecanismo de estimulación recíproca entre éstos y los acreedores chilenos para echar crecimiento al valor de las mercaderías que integraban los situados. Así, si por una parte la junta de hacienda del situado, considerando la imposibilidad de satisfacer los gastos forzosos comprometidos con el capital privado y los salarios de los soldados adulteraron, ficticiamente, el valor de las mercancías remesadas desde Lima para equilibrar la entrada de caudales con los crecidos gastos, por su parte, y de forma paralela, los acreedores privados - enterados de que serían abonados con las mercancías crecidas en su valor en Lima y recrecidas de nuevo en Concepción- resolvieron elevar también el precio de sus productos, incrementando, con ello, los gastos anuales forzosos del situado. De lo que se desprende que los soldados, por el valor contractual de sus sueldos, en medio de este contexto inflacionario y aunque los situados se enviasen íntegros a la frontera, embolsaron o pudieron adquirir menor porción de géneros y alimentos de apremiante necesidad y que, en consecuencia, hubieran de estimar la posibilidad de endeudarse con los proveedores privados bajo el aval de futuros sueldos insertos en situados venideros.

En definitiva, si bien la existencia del situado favoreció la producción y comercialización de recursos $\mathrm{y}$, en consecuencia, que hacendados, estancieros y comerciantes, tanto en Perú como en Chile, advirtieran la pertinencia de orientar parte de sus operaciones mercantiles hacia un mercado -el del avituallamiento del ejército de Araucoque, en un principio, debieron juzgar rentable, los mecanismos descritos de regulación del 
caudal, tanto en Lima como en Concepción, impidieron que la ayuda cumpliera con su primordial y más legítimo cometido: satisfacer el pago de los valedores de la defensa chilena, los soldados, quienes muertos en la cobranza, hubieron de subsistir vivos en la deuda.

\section{REFERENCIAS BIBLIOGRÁFICAS.}

ALONSO ÁLVAREZ, Luis. "La ayuda mexicana en el Pacífico: socorros y situados en Filipinas, 1565-1816”. En El secreto del Imperio español: los situados coloniales en el siglo XVIII, Coord. MARICHAL, Carlos, y GRAFENSTEIN, Johanna von, 251-294. México, D.F.: El Colegio de México, Centro de Estudios Históricos: Instituto Mora, 2012. ANDÚJAR CASTILLO, Francisco. "La privatización del reclutamiento en el siglo XVIII: el sistema de asientos”. Studia histórica. Historia Moderna no. 28 (2003): 123-147. . "Guerra, venalidad y asientos de soldados en el siglo XVIII". Studia histórica. Historia Moderna 35 (2013): 235-268.

CARMAGNANI, Marcello. Los mecanismos de la vida económica de una sociedad colonial: Chile (1680-1830). Santiago de Chile: DIBAM, 2001.

CELAYA NÁNDEZ, Yovana. Alcabalas y situados: Puebla en el sistema fiscal imperial, 1638-1742. México, D.F.: El Colegio de México Fideicomiso Historia de las Américas, 2010. . "El costo fiscal en la defensa del Caribe: la Armada de Barlovento, 17021748”. En El secreto del Imperio español: los situados coloniales en el siglo XVIII, Coord. MARICHAL, Carlos, y GRAFENSTEIN, Johanna von, 213-236. México, D.F.: El Colegio de México, Centro de Estudios Históricos: Instituto Mora, 2012.

CERDA-HEGERL, Patricia. Fronteras del Sur. La región del Bio-Bío y la Araucanía chilena, 1604-1883. Temuco: Universidad de la Frontera, 1996.

DE RAMÓN, Armando. Historia urbana. Una metodología aplicada. Buenos Aires: CLACSO - Ediciones Siap, 1978.

DE RAMÓN, Armando, y LARRAÍN, José Manuel. Orígenes de la vida económica chilena: 1659-1808. Santiago de Chile: Centros de Estudios Públicos, 1982.

DÍAZ BLANCO, José Manuel. Razón de Estado y buen gobierno. La Guerra defensiva y el imperialismo español en tiempos de Felipe III. Sevilla: Universidad de Sevilla - Secretariado de Publicaciones de la Universidad de Sevilla, 2010. 
FERRANDO KEUN, Ricardo. Y así nació la frontera: conquista, guerra, ocupación, pacificación, 1500-1900. Santiago de Chile: Ediciones Universidad Católica de Temuco, 2012.

FLORES GUZMÁN, Ramiro Alberto. "Los situados peruanos: desde Chile hasta Panamá, 1700-1800”. En El secreto del Imperio español: los situados coloniales en el siglo XVIII, Coord. MARICHAL, Carlos, y GRAFENSTEIN, Johanna von, 33-61. México, D. F.: El Colegio de México, Centro de Estudios Históricos: Instituto Mora, 2012.

FLORES MORÓN, Braulio Luis. "Los situados del Río de la Plata en el siglo XVIII”. Temas de Historia Militar no. 2 (1988): 207-220.

GASCÓN, Margarita. "La articulación de Buenos Aires a la Frontera Sur del Imperio español, 1640-1740”. Anuario IEHS no. 13 (1998): 193-213.

- "Comerciantes y redes mercantiles del siglo XVII en la frontera sur del Virreinato del Perú". Anuario de Estudios Americanos 57, no. 2 (2000): 413-448.

imperial y la agencia de la naturaleza". Revista TEFROS 6, no. 1 (2008): 1-20.

GRAFENSTEIN, Johanna von, "El papel de la Nueva España como fuente de recursos para las posesiones españolas del Gran Caribe (1779-1784)”. Homines. Revista de Ciencias Sociales 20:2 (2000): 338-355.

- "Situado y gasto fiscal: la real caja de México y las remesas para gastos militares en el Caribe, 1756-1787”. En Guerra y Fiscalidad en la América colonial, siglos XVI-XIX, Coord. ALVES CARRARA, Ángelo, y SÁNCHEZ SANTIRÓ, Ernest, 115-142. México, D.F.: Instituto Mora, Universidad Federal Juiz de Fora, 2012.

. "El situado novohispano al Circuncaribe, un análisis de su composición, distribución y modalidades de envío, 1791-1808”. En El secreto del Imperio español: los situados coloniales en el siglo XVIII, Coord. MARICHAL, Carlos, y GRAFENSTEIN, Johanna von, 143-170. México, D. F.: El Colegio de México, Centro de Estudios Históricos: Instituto Mora, 2012.

IRIGOIN, Alejandra, y GRAFE, Regina. "Bargaining for Absolutism. A Spanish Path to Nation-State and Empire Building”. The Hispanic American Historical Review 88, no. 2 (2008): 235-245. 
“Absolutismo negociado: la trayectoria hispana en la formación del Estado y el Imperio”. En El secreto del Imperio español: los situados coloniales en el siglo XVIII, Coord. MARICHAL, Carlos, y GRAFENSTEIN, Johanna von, 295-340. México, D.F.: El Colegio de México, Centro de Estudios Históricos: Instituto Mora, 2012.

JARA HANTKE, Álvaro. Guerra y sociedad en Chile: la transformación de la Guerra de Arauco y la esclavitud de los indios. Santiago de Chile: Editorial Universitaria, 1971.

. El Imperio español en América (1700-1820). Una historia económica.

Santiago de Chile: Editorial Sudamericana, 2011.

KRASELSKY, Javier "Conflictos corporativos entre comerciantes en el virreinato del Río de la Plata. La conducción de caudales de Potosí a Buenos Aires, 1795-1803”. Americanía. Revista de Estudios Latinoamericanos no. 4 (2016): 215-246.

KUETHE, Allan J. "Guns, Subsidies and Commercial Privilege: Some Historical Factors in the Emergence of the Cuban National Character, 1763-1815". Cuban Studies no. 16 (1986): 123-138.

"El situado mexicano, los azucareros y la fidelidad cubana", en Las Antillas en la era de las Luces y la revolución, editado por PIQUERAS ARENAS, José Antonio, 301318. Castellón de la Plana: Siglo XXI, 2005.

KUETHE, Allan J. y MARCHENA, Juan, Soldados del rey. El ejército borbónico en América colonial en vísperas de la Independencia. Castellón de la Plana: Universitat Jaume I, 2005.

LAVIANA CUETOS, María Luisa. Organización y funcionamiento de las Cajas Reales de Guayaquil en la segunda mitad del siglo XVIII. Sevilla: Escuela de Estudios Hispanoamericanos - CSIC, 1980.

. "Excedente fiscal y defensa del Imperio: el situado de Guayaquil a Cartagena en el siglo XVIII”. Revista del CESLA no. 11 (2008): 93-104.

. Reformismo borbónico y control fiscal: las cajas reales de Guayaquil en el siglo XVIII. Guayaquil: Biblioteca Municipal de Guayaquil, 2008.

MARCHENA FERNÁNDEZ, Juan. "La financiación militar en Indias: introducción a su estudio”. Anuario de Estudios Americanos no. 36 (1979): 81-110. 
. La institución militar en Cartagena de Indias en el siglo XVIII (1700-1810).

Sevilla: Centro Superior de Investigaciones Científicas, 1982.

- Ejército y milicias en el mundo colonial americano. Madrid: Mapfre, 1992.

. "Financiación militar y situados". Temas de Historia Militar no. 1 (1998):

261-310.

- "Capital, créditos e intereses comerciales a fines del periodo colonial: los costos del sistema defensivo americano. Cartagena de Indias y el sur del Caribe". Tiempos de América Revista de historia, cultura y territorio no. 9 (2002): 3-38.

MARICHAL, Carlos, y GRAVENSTEIN, Johanna von. El secreto del Imperio español: los situados coloniales en el siglo XVIII. México: Instituto Mora, 2012.

MARICHAL, Carlos, y SOUTO MANTECÓN, Matilde. "Silver and Situados: New Spain and the Financing of the Spanish in the Caribbean in the XVIII century". The Hispanic American Historical Review, 74, no. 4 (1994): 587-613.

. "La Nueva España y el financiamiento del Imperio español en América: los situados para el Caribe en el siglo XVIII". En El secreto del Imperio español: los situados coloniales en el siglo XVIII, Coord. MARICHAL, Carlos, y GRAFENSTEIN, Johanna von, 61-94. México, D.F.: El Colegio de México, Centro de Estudios Históricos: Instituto Mora, 2012.

MEISEL ROCA, Adolfo. "Crecimiento a través de los subsidios: Cartagena de Indias y el situado, 1751-1810”. Cuadernos de Historia económica y empresarial no. 9 (2002):1-26.

- “Situado o contrabando? La base económica de Cartagena de Indias a finales del siglo de las Luces". En Cartagena de Indias en el siglo XVIII, Coord. CALVO STEVENSON, Haroldo, y MEISEL ROCA, Adolfo. Cartagena de Indias: Banco de la República, 2005.

. "El situado de Cartagena de Indias a fines del Siglo de las Luces". En El secreto del Imperio español: los situados coloniales en el siglo XVIII, Coord. MARICHAL, Carlos, y GRAFENSTEIN, Johanna von, 193-212. México, D.F.: El Colegio de México, Centro de Estudios Históricos: Instituto Mora, 2012.

NÁTER, Laura. "Dimensiones y funciones de los situados de tabaco en La Habana del siglo XVIII". En El secreto del Imperio español: los situados coloniales en el siglo XVIII, Coord. 
MARICHAL, Carlos, y GRAFENSTEIN, Johanna von, 171-192. México, D.F.: El Colegio de México, Centro de Estudios Históricos: Instituto Mora, 2012.

OÑAT, Roberto. Régimen legal del ejército en el Reino de Chile: notas para su estudio. Santiago de Chile: Ediciones del Pacífico, 1953.

PACHECO DÍAZ, Argelia. Una estrategia imperial. El situado de España a Puerto Rico, 1765-1821. San Juan de Puerto Rico: Instituto Mora, 2005.

En El secreto del Imperio español: los situados coloniales en el siglo XVIII, Coord. MARICHAL, Carlos, y GRAFENSTEIN, Johanna von, 115-142. México, D.F.: El Colegio de México, Centro de Estudios Históricos: Instituto Mora, 2012.

REICHERT, Rafael. "El situado novohispano para la manutención de los presidios españoles en la región del Golfo de México y el Caribe durante el siglo XVII". Estudios de Historia Novohispana no. 46 (2012): 47-81.

SAGUIER, Eduardo R. "La conducción de los caudales de oro y plata como mecanismo de corrupción. El caso del situado asignado a Buenos Aires por las cajas reales de Potosí en el siglo XVIII”. Historia no. 24 (1989): 287-317.

SÁNCHEZ SANTIRÓ, Ernest. Finanzas y política en el mundo iberoamericano: del antiguo régimen a las naciones independientes, 1754-1850. México: Instituto Mora, 2001.

SERRANO ÁLVAREZ, José Manuel. "El situado en la administración militar indiana: los casos de Santa Fe y Quito, 1700-1788”. Revista de Historia Militar no. 92 (2002): 147-184. . "El gasto naval en España e Indias (1715-1759): el caso de Tierra Firme". Revista de historia naval 20, no. 77 (2002): 25-34.

- "El factor humano en la defensa de Tierra Firme: sueldos en Cartagena de Indias, 1700-1788”. Temas Americanistas no. 16 (2003): 64-80.

. Fortificaciones y tropas: el gasto militar en Tierra Firme, 1700-1788. Sevilla: Universidad de Sevilla - CSIC - Diputación de Sevilla, 2004.

. "Situados y rentas en Cartagena de Indias durante el siglo XVIII". Temas Americanistas no. 18 (2004): 58-78. . "Situados y administración militar en Texas a mediados del siglo XVIII". Temas Americanistas 18 (2005): 40-55. 
- Ejército y fiscalidad en Cartagena de Indias: auge y declive en la segunda mitad del siglo XVII. Bogotá: El Áncora, 2006.

- "Economías, rentas y situados en Cartagena de Indias, 1761-1800”. Anuario de Estudios Americanos 63, no. 2 (2006): 75-96.

. "Apuntes para una metodología del estudio del gasto militar en Indias". Temas Americanistas no. 15 (2012): 75-89.

- "Dominio, presencia militar y situados en Texas a mediados del siglo XVIII". En El secreto del Imperio español: los situados coloniales en el siglo XVIII, Coord. MARICHAL, Carlos, y GRAFENSTEIN, Johanna von, 237-250. México, D.F.: El Colegio de México, Centro de Estudios Históricos: Instituto Mora, 2012.

. "El poder y la gloria: élites y asientos militares en el astillero de La Habana durante el siglo XVIII”. Studia histórica. Historia Moderna no. 35 (2013): 99-125.

SERRANO ÁLVAREZ, José Manuel, y KUETHE, Allan J., "El situado mexicano y la Cuba borbónica". En El secreto del Imperio español: los situados coloniales en el siglo XVIII, Coord. MARICHAL, Carlos, y GRAFENSTEIN, Johanna von, 95-114. México, D. F.: El Colegio de México, Centro de Estudios Históricos: Instituto Mora, 2012.

SILVA VARGAS, Fernando. "Esquema de la Hacienda Real en Chile indiano (siglos XVI XVII)". Revista Chilena de la Historia del Derecho no. 4 (1965): 208-250.

. "La Contaduría Mayor de Cuentas del Reino de Chile". Estudios de Historia de las Instituciones Políticas y Sociales no. 2 (1967): 103-179.

- "Perú y Chile. Notas sobre sus vinculaciones administrativas y fiscales (1785 - 1800)". Historia no. 7 (1968): 147-203.

- Poder y redes: el gobernador de Chile don Francisco Ibáñez de Peralta (1700 - 1709). Santiago de Chile: Academia Chilena de la Historia, 2013.

SUÁREZ, Margarita. Comercio y fraude en el Perú colonial: las estrategias mercantiles de un banquero. Lima: Instituto de Estudios Peruanos, 1995.

. Desafios trasatlánticos: mercaderes, banqueros y el estado en el Perú virreinal, 1600-1700. Lima: Pontificia Universidad Católica del Perú. Instituto Riva-Agüero, 2001.

TEPASKE, John. La Real Hacienda de Nueva España, la Real Caja de México: 1576-1816. México, D. F.: Instituto Nacional de Antropología e Historia, 1976. 
TEPASKE, John y KLEIN, Herbert S. The Royal Treasuries of the Spanish Empire in América. Durham, N.C.: Duke University Press, 1982.

- Ingresos y egresos de la Real Hacienda de Nueva España. Culhuacán: Instituto Nacional de Antropología e Historia, 1988.

TORRES SÁNCHEZ, Jaime. "La Real Hacienda del Reino de Chile y los gastos militares”. Nueva Historia 2, no. 6 (1983): 111-129.

VARGAS CARIOLA, Juan Eduardo. "Los Austrias y el ejército de Chile". Revista Chilena de Historia del Derecho 9 (1983): 355-370.

. "Financiamiento del ejército de Chile en el siglo XVII". Historia no. 19 (1984): 159-202.

- "Antecedentes sobre levas en Indias para el ejército de Chile en el siglo XVII (1541-1662)". Historia no. 22 (1987): 335-356.

- "Notas sobre el gobierno militar en Indias: el caso del ejército de Chile en el siglo XVII". Revista Chilena de Historia del Derecho no. 15 (1991): 219-234.

. "Estilo de vida en el Ejército de Chile durante el siglo XVII". Revista de Indias no. 53 (1992): 425-458.

VILLALOBOS, Sergio. Relaciones fronterizas en la Araucanía. Santiago de Chile: Universidad Católica de Chile, 1982.

- Vida fronteriza en la Araucanía: el mito de la guerra de Arauco. Santiago de Chile: Andrés Bello, 1995.

WASSERMAN, Martin L. "El Real Situado y gestión patrimonial del recurso fiscal. Remesas para la defensa del puerto de Buenos Aires en el siglo XVII”. Nuevo Mundo Mundos Nuevos (2016): En línea. 